\title{
Affective Concomitants of Information on Morality and Competence
}

Bogdan Wojciszke

Institute of Psychology, Polish Academy of Science, Warsaw, Poland

\begin{abstract}
A research program on the affective concomitants of information on morality (M) and competence (C) is reviewed. The program originated from the assumption that $\mathrm{M}$ and $\mathrm{C}$ are the most important categories of behavior construal and that both categories can be, and are, used in interpretation of the same behavioral acts. Whereas in the observer perspective (when interpreting the behavior of others) $\mathrm{M}$ is more relevant than $\mathrm{C}$, in the actor perspective (when interpreting one's own behavior) $\mathrm{C}$ is more relevant than M. Based on these theses it was predicted and found that: (1) M-related acts of others (moral acts and transgressions) instigated stronger affective responses than C-related acts (successes and failures), (2) the opposite was true for the participant's own acts, (3) attitudes toward other persons were more strongly influenced by the M than C-related information, and (4) attitudes toward the self (self-esteem) were more strongly influenced by the $\mathrm{C}$ than M-related information. The findings were discussed in terms of $\mathrm{M}$ and $\mathrm{C}$ being differently relevant for social inclusion-exclusion processes.
\end{abstract}

Keywords: morality, competence, self vs. others, self-interest

There are hundreds of trait-descriptive terms in each European language. Although social cognition researchers tend to treat the trait content merely as a source of error variance, not all sorts of content are alike and uniform, or, as Rothbart and Park (1986) put it, "not all traits were created equal." The trait content matters in person-perception - different sorts of information are processed in different ways and they lead to various affective responses. This paper reviews a program of research showing that information on moral (M) and competence-related (C) qualities of others (and the self) are processed in different ways and, especially, that the two types of content have strikingly different affective concomitants. Inferences of $\mathrm{M}$ and $\mathrm{C}$ traits are accompanied by distinct emotions, lead to differing evaluations, and have divergent consequences for attitudes toward the self and others.

\section{Prominence of Morality and Competence in Impressions}

Several lines of social cognition research suggest that morality and competence are two important kinds of content frequently appearing in person-perception pro- cesses. As elaborated below, M traits (honest, truthful, aggressive, egoistic, etc.) refer to goals of the perceived person and relations between these goals and moral norms, as well as harms/benefits brought by these goals to other surrounding persons (observers included). C traits (capable, intelligent, inefficient, etc.) refer to the efficiency with which those moral or immoral goals are attained. $\mathrm{M}$ and $\mathrm{C}$ traits constitute two separate and basic clusters of traits in the perception of organizational leaders, and these clusters define the two classical styles of leadership: relation- and task-oriented (cf. Chemers, 2001). The two trait types appear frequently in voters' open-ended commentaries on political candidates in various countries, like the US (Kinder \& Sears, 1985) and Poland (Wojciszke \& Klusek, 1996). They constitute two separate and basic clusters in the perception of political leaders, and trait descriptions along these two dimensions are good predictors of politicians' approval.

This extends to the perception of personally known individuals from the perceiver's own social milieu. In one study we asked our participants for recollection of episodes in which they had come to a clear-cut evaluative conclusion on other people or themselves. Content analysis of over 1000 episodes showed that in three fourths of them the evaluative impression was based on M- or 
C-related considerations (Wojciszke, 1994). In another study we asked participants for global evaluations of 20 well-known persons from their social environment and ratings of their $\mathrm{M}$ and $\mathrm{C}$ traits. On average, these two types of trait ascription explained $82 \%$ of the variance of global impressions (Wojciszke, Bazinska, \& Jaworski, 1998). The same was true for the perception of participants' supervisors in three different organizations (Wojciszke, Baryla, \& Mikiewicz, 2003). A great majority of evaluative impression variance seems to be explained by $\mathrm{M}$ and $\mathrm{C}$ considerations.

\section{Theoretical Accounts of the Morality-Competence Differences}

A substantial amount of research coming from diverse areas of psychology suggests that generally "bad is stronger than good" (Baumeister, Bratslavsky, Finkenauer, \& Vohs, 2001) and people show a general negativity bias (Rozin \& Royzman, 2001). Bad events, outcomes, and pieces of information exert a stronger effect on people's responses than good ones, even when the positives and negatives are balanced for extremity. In impression formation research, it is regularly found that when equal amounts of positive and negative information on the target person are integrated, a generally negative impression arises, especially when the input information is extreme and perceived as valid. This negativity effect is typical for situations where the information on target persons pertains solely or partially to M (cf. Peeters \& Czapinski, 1990; Skowronski \& Carlston, 1989 for reviews). However, when the integrated information pertains solely to $\mathrm{C}$ a positivity effect is found (Brycz \& Wojciszke, 1992; Kubicka-Daab, 1989; Skowronski \& Carlston, 1987; Wojciszke, Brycz, \& Borkenau, 1993).

\section{Cognitive Explanations}

Two well-developed explanations of the negativity in the $\mathrm{M}$ domain and the positivity effect in the $\mathrm{C}$ domain are the schematic model of attribution (Reeder \& Brewer, 1979; Reeder, Pryor, \& Wojciszke, 1992;) and the cuediagnostics model of impression formation (Skowronski $\&$ Carlston, 1987). Both theories assume that people infer personality traits from others' actions and that in the $\mathrm{M}$ domain negative information is more decisive than positive, while the opposite is true in the $\mathrm{C}$ domain.

In Reeder's formulation this is because of differential expectations (schemas) about trait-behavior relations which people hold in the two domains. Perceivers assume that moral people behave in moral but not immoral ways, although immoral people can behave both in immoral and moral ways, because the latter are socially demanded and rewarded. In effect, moral behaviors are not informative about the underlying traits. The opposite is true for competence, because everybody can behave in incompetent ways, but only capable persons can behave in smart ways. In Skowronski's formulation the difference is due to asymmetrical diagnosticity of positive and negative behaviors in the two domains. In the $\mathrm{M}$ domain, negatives have higher diagnostic value than positives because they better discern between moral and immoral persons. In the $\mathrm{C}$ domain, positives are more exclusive than negatives, which renders the former more diagnostic for decisions about whether a person belongs to the "competent" category or not. These two accounts of negativity-positivity effects in the $M$ and $\mathrm{C}$ domain are highly convergent and have been confirmed in a sizeable amount of research using various dependent measures (cf. Reeder, 1993; Skowronski, 2002).

\section{Motivational Explanations}

An entirely different explanation of these differences arises from Peeters's (1983) distinction between selfprofitable versus other-profitable traits. This distinction is slightly more general but overlaps with $\mathrm{C}$ vs. $\mathrm{M}$ traits. Competence is self-profitable, i.e., directly and unconditionally rewarding for a person who shows this quality rather than for others (whatever one does, it is better to do it efficiently). Similarly, incompetence is unconditionally detrimental to the actor rather than to others (others may also lose from the actor's incompetence, but on the condition that their outcomes are dependent on his or her acts). The opposite is true for morality - an otherprofitable quality - which is directly rewarding for surrounding others, while immorality is directly harmful to others (and often is immediately benefiting for the perpetrator of immoral acts). It ensues, that from the point of view of an observer, a target person's morality is more relevant and leads to stronger affective responses than competence (which has relatively weak affective consequences). This may explain a negativity effect in the $M$ domain because when the incoming information is evaluatively extreme, avoidance becomes stronger than approach (and negatives acquire more weight than positives). This may also explain an opposite effect in the $\mathrm{C}$ domain because when the incoming information is evaluatively weak, approach becomes stronger than avoidance (and positives acquire more weight than negatives; cf. Cacioppo, Gardner, \& Berntson, 1997; Wojciszke, Brycz, \& Borkenau, 1993).

The M-C difference may be expressed in these self-interest terms: From the observer perspective (when responding to another's behavior), $\mathrm{M}$ is more pertinent to our self-interests than $\mathrm{C}$, but the opposite is true from the 
actor perspective (i.e., when responding to our own behavior). In addition to explaining the negativity vs. positivity effects in information integration, this differential self-interest notion has several other consequences. Some of them were explored in the research program reported below.

\section{Emotional Responses to Morality and Competence}

Yet another interesting difference between $\mathrm{M}$ and $\mathrm{C}$ traits is that their inferences are based on separate features of the observed behavior. Inferences of $M$ traits are based on the perceived person's goals and how they relate to moral norms and the well-being of other people. Whereas a negative morality is inferred when a perceived person breaks the norms or harms others, a positive morality is attributed when the person maintains the norms or benefits others. Inferences of $\mathrm{C}$, however, are based on something different - on the efficiency of goal attainment. Low competence is inferred when the perceived person fails to reach his or her goal, and high competence is inferred when the goal achievement is efficient and successful.

Moral contents of the actor's goal and efficiency of its attainment are clearly orthogonal: Both moral and immoral actions can be successful, indicating competence of their actor, but both types of goals can also remain unattained, thus showing the actor's incompetence. This suggests a $2 \times 2$ classification of actions with respect to their construal in $\mathrm{M}$ and C-related terms (Wojciszke, 1994). The first type of action is virtuous success, where the action goal is moral and successfully achieved (e.g., successfully helping a friend in math); the second is virtuous failure, where the actor aims at a moral goal but fails to achieve it (failing to help the friend); the third is sinful success, where the goal is immoral and successfully achieved (e.g., undetected cheating at an exam); and finally sinful failure, where the actor fails to achieve an intended immoral goal (being caught cheating in an exam). Wojciszke (1994) showed that the same behavioral acts can be and are construed in both ways, though not at the same time by the same person. In accordance with the logic of self-interest, observers appeared to construe observed actions in $\mathrm{M}$ rather than $\mathrm{C}$ terms, whereas actors appeared to construe their own actions in $\mathrm{C}$ rather than $\mathrm{M}$ terms. Global evaluations of others and self followed these trait inferences, e.g., virtuous failures led to a positive evaluation of others (because $\mathrm{M}$ is more relevant for an observer, such actions were perceived mainly as moral acts) but to a negative evaluation of self (be- cause $\mathrm{C}$ is more relevant for an actor or trait possessor, such actions were perceived mainly as failures).

\section{Self vs. Others}

This analysis and data have some interesting consequences for understanding emotions accompanying behavioral acts of the self and others. First, because the same negative acts may be construed both in $\mathrm{M}$ and $\mathrm{C}$ terms, it makes theoretical sense to compare moral transgressions (M) to failures (C). The same is true for positive acts, as identical acts are frequently construable both in $\mathrm{M}$ terms (as norm-maintenance behavior) and $\mathrm{C}$ terms (as successes). Second, based on the thesis of higher relevance of $\mathrm{C}$ than $\mathrm{M}$ in the actor perspective, it may be predicted that an individual's own behavior instigates more extreme emotional responses when it pertains to competence rather than morality. Similarly, based on the higher relevance of $\mathrm{M}$ than $\mathrm{C}$ in the observer perspective, it may be predicted that others' behavior instigates more extreme emotions when it pertains to morality rather than competence.

These predictions were tested in a study where half of participants were asked to recollect an episode in which they had won a success and to describe their emotional state experienced during this episode. Then they were asked to recollect a personal failure and to describe their emotional state in that situation. Another half were asked for recollection and description of episodes involving their own moral transgression or virtuous, moral behavior. These spontaneously generated descriptions of affective states were analyzed for the content of emotions listed and for general positivity-negativity of the emotional states reported (Wojciszke \& Dowhyluk, 2003). The emotion descriptors were rated for their valence, which enabled us to compute indices of the mean valence of emotions reported as responses to own or others' successes and failures, or moral and immoral acts. These indices were then subjected to analysis of variance. As illustrated in Figure 1, in the actor perspective (own behavior) we found a strong interaction between the act valence (positive-negative) and domain (M-C). Whereas within the negative acts a failure instigated more negative emotions than a moral transgression, within the positive acts a success led to more positive emotions than a moral act. Shortly, the reported emotions were more extreme when they pertained to own $\mathrm{C}$ than $\mathrm{M}$. As expected, exactly the opposite was true for emotions reported as responses to $\mathrm{C}$ and $\mathrm{M}$ of other people, as can be seen in Figure 2. Clearly, our participants reported stronger emotions in response to others' $\mathrm{M}$ (transgressions and moral acts) than $\mathrm{C}$ (failures and successes).

We also identified emotions that were more frequently reported after failure than moral transgression, as well as 


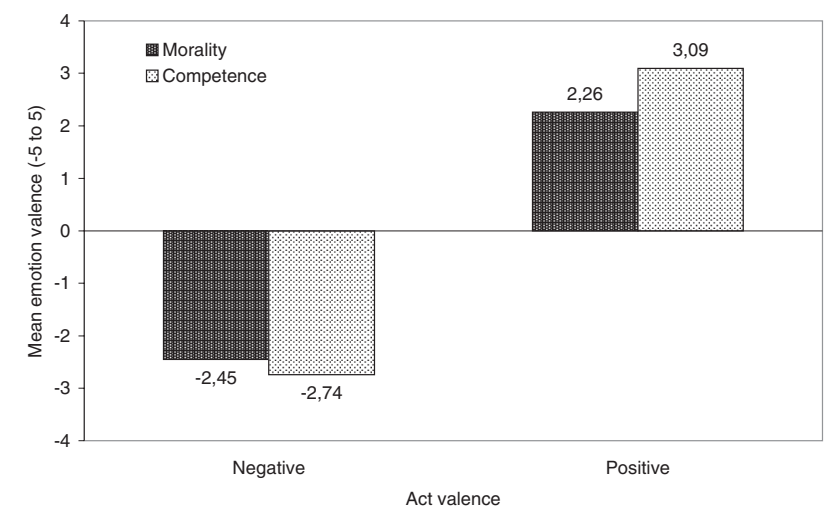

Figure 1. Mean valence of emotions reported as responses to own negative or positive acts related to morality or competence (Wojciszke \& Dowhyluk, 2003).

those that were more frequently reported after transgression than failure (separately for acts of the self and others). This content analysis showed that the two types of own negative acts instigated qualitatively distinct affective states. Whereas most emotions experienced after own failure were low arousal affects typical for dejection (Depression, Apathy, Disappointment, Sadness, and Feeling tired), most emotions experienced after own moral transgression were high-arousal affects of the agitation type (Shame, Guilt, Disgust, Fear-Anxiety, Excitation, and Uncertainty). Interestingly, these two types of emotions were suggested by the self-discrepancy theory (Higgins, 1989) to constitute distinct syndromes of emotional response to two types of self-discrepancies. According to this theory, two types of self-discrepancies cause people to suffer. First, disparity between the actual self and the ideal self (representation of attributes which one would like to possess), which results in dejection-related emotions such as dissatisfaction, helplessness, feeling blue, feeling no interest in things, feeling everything is an effort. Second, disparity between the actual and the ought self (representation of attributes which one believes he or she should possess), which results in agitation-related emotions such as guilt, irritation, feeling scared, feeling spells of terror or panic. The present results suggests that the ought self postulated by Higgins probably contains $\mathrm{M}$ contents whereas the ideal self contains mainly C-related qualities.

\section{Who the Other Is}

A comparison of Figures 1 and 2 shows not only differential interactions between the perspective (self vs. others) and domain (M vs. C), but also much lower intensity of the responses to behavior of others (compared to own behavior). Content analyses of the reported emotions

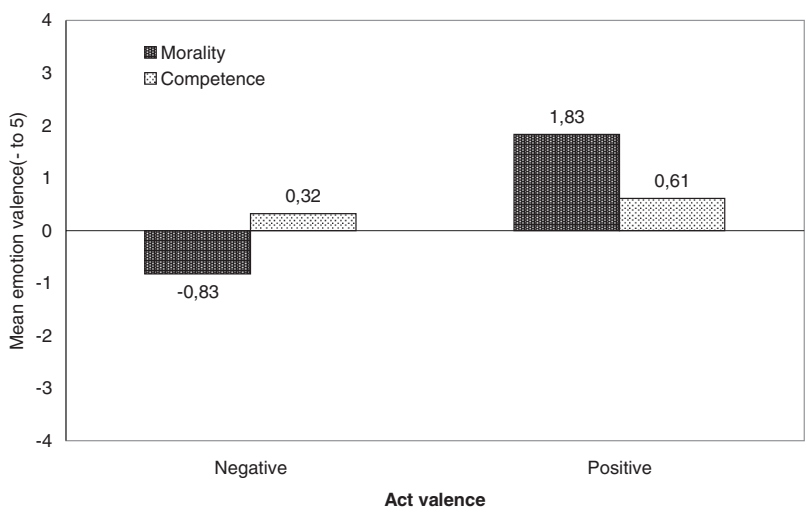

Figure 2. Mean valence of emotions reported as responses to others' negative or positive acts related to morality or competence (Wojciszke \& Dowhyluk, 2003).

showed that this was because of ambivalent responses toward others' behavior, especially acts pertaining to competence. Responses to others' failures included emotions both negative (Dismay, Sadness, Helplessness) and positive (Satisfaction, Joy, Relief). Similarly mixed were responses to others' successes (Envy, Sadness, Joy, Optimism).

However, the "other" category is very indeterminate and obviously our emotions induced by other person's behavior should depend on who, exactly, the other is. Especially, our own attitude toward the other should make an important difference as predicted by classical theories of cognitive consistency or more recent theorizing about motivations underlying the process of hypothesis testing and affective responses to hypothesis confirmation-disconfirmation (cf. Kunda, 1999). Emotions induced by positive acts (successes and moral acts) should be more positive when the acts are committed by those whom we like rather than dislike. This is because positive acts committed by the former maintain cognitive consistency and confirm our attitude-based expectancies (which results in additional positivity of emotional response), whereas the same acts committed by a disliked person introduce discomforting imbalance or dissonance and disconfirm our expectations. By the same logic, emotions induced by negative acts of others (failures and moral transgressions) should be more negative when the acts are committed by those whom we like.

To test these predictions we performed another series of studies using a similar method, but asking this time for recollection of episodes and reporting emotions instigated by actions of another person who was liked or disliked by the participants (Wojciszke \& Szymków, 2003). As can be seen in Figure 3, the pattern of results appeared strikingly different for $\mathrm{C}$ and $\mathrm{M}$ domains. Emotional responses to other's successes and failures depended solely on whether the other was liked or disliked. The success 


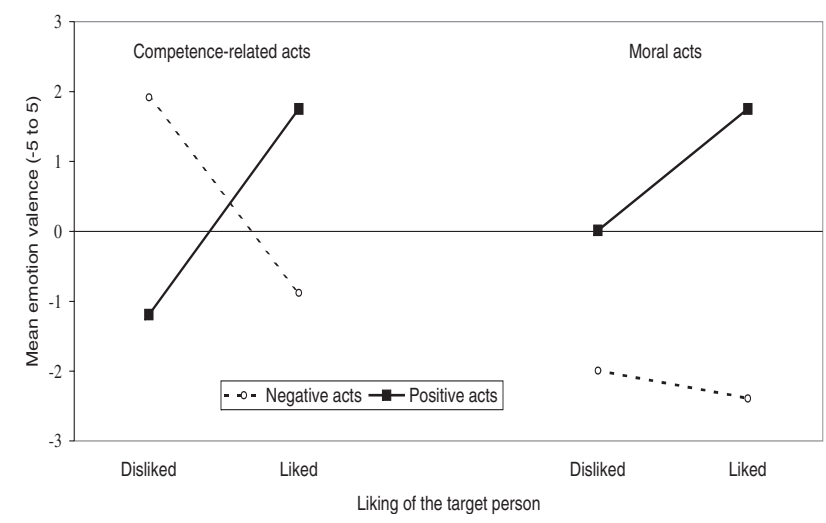

Figure 3. Mean valence of emotions reported as responses to competence-related and moral acts committed by a person who was liked or disliked by the participants (Wojciszke \& Szymków, 2003).

of another person seems not to have any inherent positive value - it induces positive emotions when we like the person, but it brings negative responses when the person is disliked. The failure of others is a simple inversion of this pattern. So, the way our own self and attitudes are implicated depends entirely on affective responses to C of others.

The story is quite different for the M domain. Moral transgressions always led to negative emotions, independently of who committed them, but positive moral acts led to positive emotions only when performed by persons liked by the participant. When the person was disliked, responses were strongly ambivalent, including both Satisfaction and Dissatisfaction, Surprise, and, especially, Uncertainty/doubt. As many as $28 \%$ of participants used the latter term to describe their emotional state after moral acts of a disliked person compared to only $5 \%$ who responded in this way to a moral act by a person whom they liked. So, immoral behavior is inherently negative, whereas moral behavior is very ambiguous (as recognized by numerous authors). Interestingly, the perceiver's own attitude toward the actor serves as a strongly disambiguating factor.

Although the results reported in Figures 1-3 seem to make an internally consistent pattern, the method used in these studies is not free of limitations. First, participants were asked to recollect various episodes concerning their own or others' behavioral acts, so the results may reflect not only emotional processes but also some peculiarities of memory. This suggests a need for further studies were participants would respond to some currently experienced (not recollected) episodes. The second limitation has to do with heavy reliance on language to tap the emotional process. Because participants were asked for names of their emotional states experienced in specific situations (e.g., in the face of a transgression of a disliked person), the results may also reflect the structure of lan-

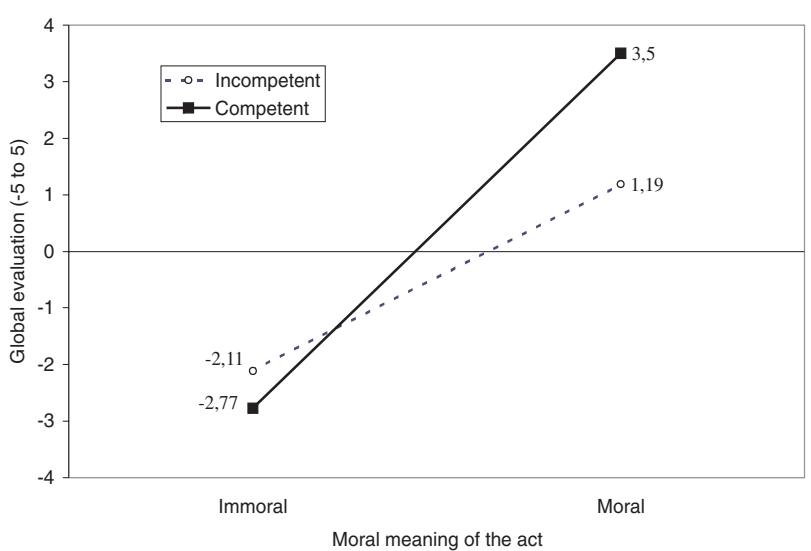

Figure 4. Global evaluations of a person whose behavioral acts were moral vs. immoral and competent vs. incompetent (Wojciszke, Bazinska, \& Jaworski, 1998).

guage used in our culture to describe emotions in various situations. Therefore, I turn to another line of our research which yielded converging evidence although attitudinal responses (not descriptions of own emotions) were used to measure affective concomitants of morality and competence.

\section{Attitudinal Consequences of Morality and Competence}

Consistent with the logic of self-interest, which is differently implicated in the $\mathrm{M}$ and $\mathrm{C}$ domain, people show stronger affective responses toward others' $\mathrm{M}$ than $\mathrm{C}$ and toward own $\mathrm{C}$ than $\mathrm{M}$. The presented reports of affective responses are closely paralleled by the data on $\mathrm{M}$ and $\mathrm{C}$ as predictors of attitudes toward the self and others.

\section{Attitudes Toward Others: Dominance of Morality}

The self-interest notion leads to the prediction that attitudes toward other persons should be more strongly influenced by the information on $\mathrm{M}$ than $\mathrm{C}$ of others. Even if $\mathrm{C}$ and $\mathrm{M}$ descriptive trait names are equally saturated with evaluative meaning (i.e., balanced in their out-ofcontext valence or favorability) the information on others' $M$ should influence evaluative impressions to a higher degree because it is more directly relevant for the perceiver's self-interest than the information on others' C. The idea that global evaluative impressions are to a higher degree influenced by $\mathrm{M}$ than $\mathrm{C}$ information on target persons was tested in a series of studies using various methods and pertaining to various phases of the impres- 
sion formation process (Wojciszke, Baziñska, \& Jaworski, 1998). It was predicted and found that:

1) Chronically accessible descriptors of others were more strongly related to $\mathrm{M}$ than $\mathrm{C}$ ( 10 traits listed most frequently by the participants as the most important in other people were: Sincere, Honest, Cheerful, Tolerant, Loyal, Intelligent, Truthful, Unselfish, Reliable, Kind, only two of them were related to C - intelligent and reliable);

2) When forming global impressions of others, the participants were more interested in gathering information on M traits (such as Fair, Honest, and Sincere) than $\mathrm{C}$ traits (such as Competent, Efficient, and Intelligent);

3) Global impressions of real persons were better predicted from the $\mathrm{M}$ than $\mathrm{C}$ trait ascription (these two types of ascription accounted for $53 \%$ and $29 \%$ of the variance of global evaluations);

4) Positivity-negativity of a global evaluative impression of fictitious target persons was based mainly on the $\mathrm{M}$ content of their behavior, while $\mathrm{C}$ information served only as a relatively weak modifier of impression intensity;

5) Whereas evaluative implications of $M$ information were strong and stable, evaluative implications of $\mathrm{C}$ information were much weaker and dependent on the accompanying $\mathrm{M}$ information.

The last two points are illustrated in Figure 4, which presents the results of an experiment where behavioral information on a target person was varied factorially in a 2 (moral-immoral) $\times 2$ (competent-incompetent) design. Although both types of information influenced global impressions, M exerted a much stronger effect $\left(\eta^{2}\right.$ $=.95)$ than $\mathrm{C}\left(\eta^{2}=.41\right)$. Moreover, when $\mathrm{M}$ information was negative, the global impressions were always negative (even when the $\mathrm{C}$ input information was positive); but when $\mathrm{M}$ information was positive, the impressions were always positive. Interestingly, when the target's behavioral acts were immoral, high $\mathrm{C}$ led to more negative impression than low $\mathrm{C}$, because the former means a higher efficiency in wrong-doing (as in the case of a thief or a con-man - such a person is more harmful when competent rather than incompetent). Moral meaning of an act can, then, radically change evaluative implications of an accompanying competence, but not the other way around (cf. Peeters, 1992).

Altogether, this series of studies showed that the descriptive content of input information plays an important role in shaping global evaluations, beyond and above the influences of a merely evaluative meaning (in contrast to the traditional cognitive algebra approach, which assumes that evaluative meaning of input information is processed independently of its descriptive content). Oth- er European authors have also found that global evaluation depends to a higher degree on M than C-related information (De Bruin \& Van Lange, 1999; Martijn et al., 1992; Vonk, 1996).

Though impressions of others are more strongly influenced by information on $\mathrm{M}$ than $\mathrm{C}$, this regularity is context-sensitive. It ceases to be true when the target's C contributes to the perceivers' well-being as much as their own abilities do, as in the case of C of "my lawyer" or "my boss." We found that employees based global evaluations of their supervisors to a higher degree on the latter's C than M (Wojciszke, Baryla, \& Mikiewicz, 2003). This was true, however, only in efficiency-oriented organizations, like competitive business where employees' outcomes increase with the $\mathrm{C}$ of their supervisor. It did not hold in bureaucratic organizations, like state administration, where $\mathrm{C}$ of the boss does not contribute to employees' outcomes (in Poland salaries in such organizations depend on bureaucratic criteria rather than efficiency, so the competence of a boss is a source of trouble rather than benefit for his or her underlings).

\section{Attitudes Toward Self: Dominance of Competence}

The same logic which predicts the dominance of $\mathrm{M}$ over $\mathrm{C}$ information in the perception of others allows a prediction of dominance of C over M in self-perception. Some initial support for this thesis was obtained in a study where participants interpreted behaviors construable in both $\mathrm{M}$ and $\mathrm{C}$ terms. As already mentioned, when behavior of others was interpreted, its construal tended to be based much more on $\mathrm{M}$ than C. However, when participants imagined that it was their own behavior or reconstructed the interpretations of persons who performed the behavior, its construal was based much more on C (efficiency of the goalattainment) than $\mathrm{M}$ (moral content of the goal) considerations (Wojciszke, 1994). Similar increases in C-related interpretations of ambiguous behavior were observed after priming the perspective of self (rather than that of other people) (Wojciszke, 1997). Finally, the results presented in Figure 1 suggest that affective responses toward own failures and successes are more extreme than responses to own transgressions and moral acts.

The closest parallel of global evaluations of others or interpersonal attitudes is self-esteem (which is understood here as an affective response toward the self, whereas perceived self-competence and self-morality is understood as important but more specific parts of selfconcept). To complete the argument that $\mathrm{C}$ dominates self-attitudes (just like $\mathrm{M}$ dominates interpersonal attitudes) it should be shown that self-esteem depends to a higher degree on $\mathrm{C}$ than $\mathrm{M}$ information. To test this hy- 
Table 1. Mean self-evaluations of moral and competence-related traits and their values as predictors of various indices of self-esteem in four samples (regression analyses) (Wojciszke, 2004).

\begin{tabular}{|c|c|c|c|}
\hline & Mean & $S D$ & $\beta$ \\
\hline \multicolumn{4}{|c|}{ Dependent measure: Self-esteem ( $N=153$, university students) } \\
\hline moral traits & 5.39 & 0.71 & .05 \\
\hline competence traits & 4.84 & 0.90 & $.53 * * *$ \\
\hline$t$ (difference) & $5.97 * * *$ & & \\
\hline \multicolumn{4}{|c|}{ Dependent measure: Self-esteem $(N=53$, state clerks $)$} \\
\hline moral traits & 6.32 & 0.72 & .11 \\
\hline competence traits & 5.76 & 0.71 & $.45 * *$ \\
\hline$t$ (difference) & $5.18 * * *$ & & \\
\hline \multicolumn{4}{|c|}{ Dependent measure: Narcissism ( $N=162$, employees of a financial firm) } \\
\hline moral traits & 5.52 & 0.82 & -.06 \\
\hline competence traits & 5.12 & 0.76 & $.45^{* * *}$ \\
\hline$t$ (difference) & $5.54 * * *$ & & \\
\hline \multicolumn{4}{|c|}{ Dependent measure: Self-promotion ( $N=106$, high school students) } \\
\hline moral traits & 5.16 & 0.89 & -.14 \\
\hline competence traits & 5.02 & 0.92 & $.36 * * *$ \\
\hline$t$ (difference) & 1.34 & & \\
\hline
\end{tabular}

Note. Self-rating on a scale ranging from 1 to 7 with 4 being the middle point. $* p<.05, * * p<.01, * * * p<.001$

pothesis four samples were asked for self-ascription of seven M traits (Fair, Good, Honest, Loyal, Selfless, Sincere, Truthful) and seven $\mathrm{C}$ traits (Clever, Competent, Efficient, Energetic, Intelligent, Knowledgeable, Logical). These traits were carefully balanced for favorability and the degree of M- vs. C-relatedness. In addition, participants filled out various measures of self-esteem. In two samples it was Rosenberg's scale, in one sample Narcissism Personality Inventory (NARPI), the most frequently used measure of narcissism, and in one sample a measure of self-promotion as a self-presentation style (i.e., the chronic tendency to present oneself as highly competent, deserving praise and promotion). Despite a great differentiation of samples and measures of self-esteem, the results convergently showed a much higher influence of $\mathrm{C}$ than $\mathrm{M}$ on self-esteem. Indeed, moral trait ascriptions were not correlated with self esteem at all, as can be seen in Table 1. Because these results are correlational, caution must be exercised in their interpretation, of course. However, a great majority of experimental studies on the state of self-esteem used the $\mathrm{C}$ information (on successes vs. failures) as a manipulation of self-esteem (cf. Sedikides \& Strube, 1997; a small number of studies varying information on social exclusion seem to be an exception from this rule, cf. Leary, 2002), which suggests efficiency of this manipulation of self-esteem, as well as inefficiency of other manipulations.

It should be noted that the lack of correlation between self-ascription of $\mathrm{M}$ and self-esteem is not at odds with the well-documented Muhammad-Ali effect - a tenden- cy to ascribe to oneself a higher degree of morality than competence (Allison, Messick \& Goethals, 1989), probably because $M$ is seen as more strongly related to the general value of a person than C (Van Lange \& Sedikides, 1998). The Muhammad-Ali effect refers to the relative levels of M- and C-trait ascription, not to their relation with self-esteem. Moreover, in three of four samples studied, the $\mathrm{M}$ ascription was reliably higher than $\mathrm{C}$ ascription (i.e., the Muhammad Ali effect was found, cf. Table 1). Still, M did not correlate with self-esteem, although $\mathrm{C}$ did. One obvious explanation of this pattern would be in terms of a ceiling effect - maybe all people ascribe to themselves $\mathrm{M}$ traits to such a high degree, that there is lack of variability in the M self-ascription and, therefore, lack of its co-variability with anything else, self-esteem included. However, this seems not plausible because in none of the samples was the variance of Mascription significantly smaller than the variance of Cascription, as can be seen in Table 1. Moreover, the average $\mathrm{M}$-ascription approached the maximum end of the 1-7 rating scale in only one of the samples (clerks); in the remaining samples these values were well below the maximum (cf. Table 1), rendering the ceiling-effect explanation implausible.

The lack of correlation between self-ascription of $\mathrm{M}$ and self-esteem is perplexing and needs further research as discussed later. Still, the main pattern of findings presented in Table 1 - that $\mathrm{C}$-ascription is more related to self esteem than M-ascription - is entirely consistent with the present thesis of the dominance of competence in self-perception and self-attitudes. 


\section{General Discussion}

The results reviewed here suggest clearly that affective responses to others' morality-immorality are consistently stronger than responses to others' competence-incompetence. Just the opposite is true for the affective responses to one's own behavior. Both these regularities were found using divergent methods (emotion reports and attitudinal responses) and may be parsimoniously explained in terms of the self-interest relevance.

Morality of others is more relevant to the self-interests of a perceiver than their competence, so perceivers respond in a more affective way to others' morality. Interestingly, this tendency to give priority to $\mathrm{M}$ over $\mathrm{C}$ information is so deep-rooted that it appears automatic. Using the Stroop paradigm, Wentura, Rothermund, and Bak (2000) showed a greater interference (slower color-naming times) in naming the color of a word flashed on a screen when the word was other-relevant (like Pushy or Kind) compared to selfrelevant words (like One-sided or Intelligent). Altogether, attitudes toward others are driven by information on their $\mathrm{M}$ to a much higher degree than by information on their $\mathrm{C}$, even if the two types of information are controlled for valence, extremity, and amount. On the other hand, own competence is more relevant to the self-interest of a perceiver than his or her morality, therefore perceivers respond to their own competence in a more affective way. Own successes and failures lead to more intense emotions than moral and immoral acts, and self-esteem is more strongly related to own competence than morality. This is despite the fact that people ascribe to themselves $\mathrm{M}$ to a higher degree than $\mathrm{C}$ (and ascribe to themselves more morality than to others, cf. Messick et al., 1985).

\section{Alternative Explanations}

A question arises as to whether these findings can be explained in other ways alternative to the present explanation in terms of divergent implications of $\mathrm{M}$ and $\mathrm{C}$ for self-interest. The first alternative explanation could be that differential influences of $\mathrm{M}$ and $\mathrm{C}$ on affective responses reflect simply their differences in value or global favorability. However, in all studies where M- versus C-trait ascriptions were compared, the two sorts of trait names were carefully balanced for their favorability (ratings of general valence on a scale ranging from -5 to 0 to 5). Simple differences in favorability of $\mathrm{M}$ and $\mathrm{C}$ cannot explain the present pattern of results, especially the sharp differences in affective concomitants of the selfversus others-perception (in both these cases $\mathrm{M}$ and $\mathrm{C}$ was measured in the same way).

The second alternative explanation could be framed in terms of controllability. Moral qualities are much more controllable than competence-related ones, especially on the negative extreme - nobody chooses inability or incompetence, but acts of dishonesty, unkindness, and so on, are usually a matter of choice. Because people can be held more responsible for their $\mathrm{M}$ than $\mathrm{C}$, this explains why attitudes toward others are influenced to a higher extent by $\mathrm{M}$ than $\mathrm{C}$ information or trait ascription. However, if controllability and responsibility were the crucial factors, selfascribed morality should be more strongly related to selfesteem than self-ascribed competence. Actually, the opposite was found in the present research and, moreover, own moral-immoral acts instigated less extreme responses than own successes and failures. This renders the controllability/responsibility explanation implausible.

A third explanation could start from the stronger correlation between self-esteem and self-ascribed $C$ than $\mathrm{M}$. Whereas $\mathrm{C}$ is a typically individualistic quality, $\mathrm{M}$ is typically collectivistic. Since all the samples studied here come from a broadly defined individualistic (Polish) society, the finding of a stronger relation between $\mathrm{C}$ and self-esteem may reflect not individual functioning but rather a cultural norm that prescribes putting more weight on efficiency than virtue. This reasoning is consistent with several findings of social psychology, especially involving the better-than-average effect, i.e., the tendency to perceive the self as better on positive trait-dimensions than an average person (so, the average participant thinks themselves to be more intelligent or a better driver than an average person coming from the same population). Persons coming from collectivistic societies (e.g., Japan) were found not to show the better-than-average effect typical for individualistic societies (Markus \& Kitayama, 1991). Together with other similar findings (e.g., involving attributions of successes and failures), this led to a suggestion that self-enhancement, or striving for high self-esteem in general, may be not a universal human motive but rather a tendency specific to individualistic societies. However, when the better-than-average effect was pursued for ratings of individualistic and collectivistic traits separately, participants coming from a collectivistic culture showed a stronger self-enhancement on collectivistic trait self-ascription, while participants coming from an individualistic culture showed a stronger self-enhancement on individualistic traits (Sedikides, Gaertner \& Toguchi, 2003). So, persons coming from both cultures showed the self-enhancement motive but in different content domains, according to the latter's importance based on cultural values (and the better-than-average effect is generally stronger for highly valued qualities Alicke, et al., 1995). Since agentic qualities are highly valued in individualistic societies, they probably constitute the core of an individualistic self-identity and this may explain why self-esteem appeared in our re- 
search so strongly correlated with the self-perceived competence. This suggests an interesting avenue for further research: studying participants from various cultures with the expectation that those coming from collectivistic societies will show a stronger relation between morality self-ascription and self esteem.

However, it is doubtful whether this "individualistic identity" notion can explain the whole pattern of results reported here. If individualistic culture shaped the selfidentity and made competence a more important constituent of the self than morality, the same should be also true of representations of other persons, especially in-groups. Several lines of research show that representation of self and in-groups are closely inter-linked: There is a substantial overlap between representations of the self and a typical in-group, close others and in-groups are included into self, and self serves the function of a default representation of an in-group (cf. Forgas \& Williams, 2002). All this suggests that what is highly valued in the self, should also be important in others. If $\mathrm{C}$ is important in individualistic societies, it should heavily influence both the self-perception and perception of others; if $\mathrm{M}$ is unimportant it should influence them both weakly, if at all. This is not what was found in the present research - actually, C appeared very important in self-perception but $\mathrm{M}$ was crucial in the perception of others.

\section{Directions of Future Research}

The basic finding that people care more about their $\mathrm{C}$ than $\mathrm{M}$ while responding in the exactly opposite way to other persons inspires, then, an interesting idea of cross-cultural studies searching for the relative importance of the two content domains not only in the perception of self (which has been studied extensively), but also in the perception of others (which has been neglected in previous studies). If cultural values matter, then $\mathrm{M}$ should dominate the perception of both self and others in collectivistic societies, while $\mathrm{C}$ should dominate both these processes in individualistic societies. If the self-interest matters, then M should dominate the perception of others but $\mathrm{C}$ should dominate the self-perception, independently of whether perceivers come from an individualistic or collectivistic culture.

Another possible line of research stems from confrontation of present findings with the sociometer theory of self-esteem (Leary \& Baumeister, 2000). This theory assumes that the main function of self-esteem is to monitor and counteract the danger of social exclusion. The latter is posited to be the main factor decreasing self-esteem. Indeed, several experiments where participants solved a task in groups and subsequently were excluded from further participation ostensibly by other group members, showed that social exclusion decreased, while inclusion increased, self-esteem (Leary, 2002). However, it is unclear how the participants construed the reason of their exclusion - they were just informed that others had not selected them for participation in a next task. Because of the task context, it is possible that the rejection was read as based mainly on their incompetence showed throughout the task and the participants responded in line with the present findings of $\mathrm{C}$ being strongly related to self-esteem. On the other hand, it would be interesting to check how people respond for rejection based on moral reasons. Since affective responses to others are driven mainly by information on their M, immorality may be a stronger reason for social exclusion than incompetence. Still, if self-esteem is really more strongly based on $\mathrm{C}$ than $\mathrm{M}$, then incompetence may be a stronger reason for social exclusion. To solve this puzzle, let me discuss the ways in which $\mathrm{M}$ and $\mathrm{C}$ are implicated in social inclusion-exclusion processes.

Everybody feels moral, including convicted thieves, robbers, and even murderers (cf. Baumeister, 1998). This universality together with the tendency to ignore the moral meaning of one's own behavior (and to stress instead its competence meaning - Wojciszke, 1994), as well as the lack of relations between self-esteem and self-ascribed morality gives the latter a strong a priori flavor. It looks as if morality is ascribed to the self independently of any facts and other self-judgments (in most our samples, the M selfjudgments were unrelated to the $\mathrm{C}$ self-judgments, although in the judgments of others $\mathrm{M}$ and $\mathrm{C}$ were highly correlated). Probably this is because people are strongly motivated to social inclusion and have a universal need to belong. People are quick to establish social attachments and resist the dissolution of existing bonds (Baumeister \& Leary, 1995). And the consequences of social exclusion are serious - it leads to emotional stress, reduction of intelligent thought, and causes self-defeating behavior (Baumeister, Twenge, \& Nuss, 2002; Twenge, Catanese, \& Baumeister, 2002). Although people can be excluded for a variety of reasons depending on the social context (especially the sort of an excluding group), immorality may be the most universal cause of exclusion. Some groups exclude people lacking intelligence, creativity, or some special abilities, but probably all social groups exclude people considered dishonest, immoral, disloyal, and unfair.

Moreover, morality applies to roughly everyone in the same way, whereas competence may by much more individualized. In a social group marked by division of labor, everyone may be expert in a different task. A person may be incompetent at some particular task without losing his or her value to the group, because the person may be good at something else, and probably self-evaluations of competence are based mainly on these areas of expertise. The crucial task for an individual is to find a niche in the group by developing some special competence that can make oneself valuable. Hence, in judging 
the self, competence is central. On the other hand, the harms of immorality are more widespread and stable than those of incompetence. If Joe is incompetent in math, for example, that has no effect on me, unless I am foolish enough to hire him as my accountant. But if he is a liar and cheater, he represents a danger to me in many ways, and any dealing I have with him could be harmful or costly to me. Generally, when a person is immoral, he or she breaks rules that everyone shares and it is safer for surrounding others to conclude from one sign of immorality that the person should be rejected. Hence, in judging others, morality is central. But in judging the self, an inference of immorality seems to be a psychological impossibility, because it would mean a generalized expectancy of (deserved) exclusion. Therefore judgments of own morality become a priori positive (meaning "I deserve inclusion"), which helps to explain the lack of correlation between $\mathrm{M}$ self-ascription and self-esteem. It also leads to a prediction that self-esteem should be less moved by incoming information about own immoral performance (than by C-related performance) possibly through stronger rejection of such information and questioning its validity. To the best of my knowledge, this hypothesis has been neither formulated nor pursued empirically and it remains to be tested in future research.

To conclude, all this does not mean that self-interest is the only factor influencing affective responses and attitudes toward others and the self. Obviously, maximization of self-interest is not the sole principle motivating behavior and social cognition (cf. Van Lange, 2000). It is nevertheless the basic fact of life. It is also the basic presumption of many important concepts and tenets of psychology, like reinforcement, motive, self-presentation, attitude, and subjective utility models of decision making, to name just a few. The present line of studies shows, I believe, that the notion of self-interest is also indispensable to understand the differences between the use of moral and competencerelated categories and, in effect, important differences in affective responses toward the self and others.

\section{Acknowledgment}

Part of this research was supported by the Alexander von Humboldt Foundation. I want to thank Wiesiek Baryla for discussions and three anonymous reviewers for valuable suggestions.

\section{References}

Alicke, M.D., Klotz, M.L., Breitenbecher, D.L. Yurak, T.J., \& Vredenburg, D.S. (1995). Personal contact, individuation, and the better-than-average effect. Journal of Personality and Social Psychology, 49, 1621-1630.

Allison, S.T., Messick, D.M., \& Goethals, G.R. (1989). On being better but not smarter than others: The Muhammad Ali effect. Social Cognition, 7, 275-296.

Baumeister, R.F. (1998). The self. In D.T. Gilbert, S.T. Fiske, \& G. Lindzey (Eds.), Handbook of social psychology (4th ed., pp. 680-740). New York: McGraw-Hill.

Baumeister, R.F., Bratslavsky, E., Finkenauer, C., \& Vohs, K.D. (2001). Bad is stronger than good. Review of General Psychology, 5, 323-370.

Baumeister, R.F., \& Leary, M.R. (1995). The need to belong: Desire for interpersonal attachments as a fundamental human motivation. Psychological Bulletin, 117, 497-529.

Baumeister, R.F., Twenge, J.M., \& Nuss, C.K. (2002). Effects of social exclusion cognitive processes: Anticipated aloneness reduces intelligent thought. Journal of Personality and Social Psychology, 83, 817-827.

Brycz, H., \& Wojciszke, B. (1992). Personality impressions on ability and morality trait dimensions. Polish Psychological Bulletin, 23, 223-236.

Cacioppo, J.T., Gardner, W.L., \& Berntson, G.G. (1997). Beyond bipolar conceptualizations and measures: The case of attitudes and evaluative space. Personality and Social Psychology Review, 1, 3-25.

Chemers, M.M. (2001). Leadership effectiveness: An integrative review. In M.A. Hogg \& R.S. Tindale (Eds.), Blackwell handbook of social psychology: Group processes (pp. 376-399). Oxford: Blackwell.

De Bruin, E.N.M., \& Van Lange, P.A.M. (1999). Impression formation and cooperative behavior. European Journal of Social Psychology, 29, 305-328.

Forgas, J.P., \& Williams, K.D. (Eds.), (2002). The social self. Cognitive, interpersonal, and intergroup perspectives. New York: Psychology Press.

Higgins, E.T. (1989). Self-discrepancy theory: What patterns of self-beliefs cause people to suffer? In M.P. Zanna (Ed.) $A d$ vances in experimental social psychology (Vol.22, pp.93136). New York: Academic Press.

Kinder, D.R., \& Sears, D.O. (1985). Public opinion and political action. In G. Lindzey \& E. Aronson (Eds.) Handbook of social psychology (3rd ed., Vol. 2, pp. 659-741). New York: Random House.

Kubicka-Daab, J. (1989). Positivity and negativity effects in impression formation: Differences in processing information about ability and morality dispositions. Polish Psychological Bulletin, 20, 295-307.

Kunda, Z. (1999). Social cognition. Making sense of people. Cambridge, MA: MIT Press.

Leary, M. (2002). The interpersonal basis of self-esteem. Death, devaluation, or deference? In J. Forgas \& K.D. Williams (Eds.) The social self: Cognitive, interpersonal, and intergroup perspectives (pp. 143-159). New York: Psychology Press.

Leary, M., \& Baumeister, R.F. (2000). The nature and function of self-esteem: Sociometer theory. In M.P. Zanna (Ed.) Advances in experimental social psychology (Vol. 32, pp. 1-62). New York: Academic Press.

Markus, H.R., \& Kitayama, S. (1991). Cultural variation in the self concept. In G.R. Goethals \& J. Strauss (Eds.) Multidisciplinary perspectives on the self (pp. 18-48). New York: Springer-Verlag.

Martijn, C., Spears, R., Van der Pligt, J., \& Jakobs, E. (1992). Negativity and positivity effects in person perception and inference: Ability versus morality. European Journal of Social Psychology, 22, 453-463.

Messick, D.M., Bloom, S., Boldizar, J.P., \& Samuelson, C.D. (1985). Why we are fairer than others. Journal of Experimental Social Psychology, 21, 480-500.

Peeters, G. (1983). Relational and informational pattern in social 
cognition. In W. Doise \& S. Moscovici (Eds.) Current issues in European social psychology (pp. 201-237). Cambridge: Cambridge University Press.

Peeters, G. (1992). Evaluative meanings of adjectives in vitro and in context: Some theoretical implications and practical consequences of positive-negative asymmetry and behavioral-adaptive concepts of evaluation. Psychologia Belgica, 32, 211231.

Peeters, G., \& Czapinski, J. (1990). Positive-negative asymmetry in evaluations: The distinction between affective and informational negativity effects. In W. Stroebe \& M. Hewstone (Eds.) European review of social psychology (Vol. 1, pp. 36-60). New York: Wiley.

Reeder, G.D. (1993). Trait-behavior relations and dispositional inference. Personality and Social Psychology Bulletin, 19, 586-593.

Reeder, G.D., \& Brewer, M.B. (1979). A schematic model of dispositional attribution in interpersonal perception. Psychological Review, 86, 61-79.

Reeder, G.D., Pryor, J.B., \& Wojciszke, B. (1992). Trait-behavior relations in social information processing. In G. Semin \& K. Fiedler (Eds.) Language and social cognition (pp. 37-57). Beverly Hills: Sage.

Rosenberg, S., \& Sedlak, A. (1972). Structural representations of implicit personality theory. In L. Berkowitz (Ed.) Advances in experimental social psychology (Vol. 6, 235-297). New York: Academic Press.

Rothbart, M., \& Park, B. (1986). On the confirmability and disconfirmability of trait concepts. Journal of Personality and Social Psychology, 50, 131-142.

Rozin, P., \& Royzman, E.B. (2001). Negativity bias, negativity dominance, and contagion. Personality and Social Psychology Review, 5, 296-320.

Sedikides, C., Gaertner,L., \& Toguchi, Y. (2003). Pancultural selfenhancement. Journal of Personality and Social Psychology, 84, 60-79.

Sedikides, C., \& Strube, M.J. (1997). Self-evaluation: To thine own self to be good, to thine own self to be sure, to thine own self to be true, and to thine own self to be better. In M.P. Zanna (Ed.), Advances in experimental social psychology (Vol. 29, pp. 209-269). New York: Academic Press.

Skowronski, J.J. (2002). Honesty and intelligence judgments of individuals and groups: The effects of entity-related behavior diagnosticity and implicit theories. Social Cognition, 20, 136169.

Skowronski, J.J., \& Carlston, D.E. (1987). Social judgment and social memory: The role of cue diagnosticity in negativity, positivity, and extremity biases. Journal of Personality and Social Psychology, 52, 689-699.

Skowronski, J.J., \& Carlston, D.E. (1989). Negativity and extremity biases in impression formation: A review of explanations. Psychological Bulletin, 105, 131-142.

Twenge, J.M., Catanese, K.H., \& Baumeister, R.F. (2002). Social exclusion causes self-defeating behavior. Journal of Personality and Social Psychology, 83, 606-615.

Van Lange, P.A.M. (2000). Beyond self-interest: A set of propositions relevant to interpersonal orientations. In W. Stroebe \& M. Hewstone (Eds.), European review of social psychology (Vol. 11, pp. 297-331). New York: Wiley.

Van Lange, P.A.M., \& Sedikides, C. (1998). Being more honest but not necessarily more intelligent than others: Generality and explanations for the Muhammad Ali effect. European Journal of Social Psychology, 28, 675-680.

Vonk, R. (1996). Negativity and potency effects in impression formation. European Journal of Social Psychology, 26, 851865.

Wentura, D., Rothermund, K., \& Bak, P. (2000). Automatic vigilance: The attention-grabbing power of approach- and avoidance-related social information. Journal of Personality and Social Psychology, 78, 1024-1037.

Wojciszke, B. (1994). Multiple meanings of behavior: Construing actions in terms of competence or morality. Journal of Personality and Social Psychology, 67, 222-232.

Wojciszke, B. (1997). Parallels between competence- versus morality-related traits and individualistic versus collectivistic values. European Journal of Social Psychology, 27, 245-256.

Wojciszke, B. (2004). Competence, morality, and self-esteem. Unpublished manuscript.

Wojciszke, B., Baryla, W., \& Mikiewicz, A. (2003). Liking and respect as two dimensions of interpersonal attitudes. Manuscript under review.

Wojciszke, B., Bazinska, R., \& Jaworski, M. (1998). On the dominance of moral categories in impression formation. Personality and Social Psychology Bulletin, 24, 1245-1257.

Wojciszke, B., Brycz, H., \& Borkenau, P. (1993). Effects of information content and evaluative extremity on positivity and negativity biases. Journal of Personality and Social Psychology, 64, 327-336.

Wojciszke, B., \& Dowhyluk, M. (2003). Emotional responses toward own and others' behavioral acts related to competence and morality, Polish Psychological Bulletin, 34, 1430-151.

Wojciszke, B., \& Klusek, B. (1996). Moral and competence-related traits in political perception. Polish Psychological Bulletin, 27, 319-325.

Wojciszke, B., \& Szymków, A, E. (2003). Emotions related to others' competence and morality, Polish Psychological Bulletin, 34, 135- 142 .

About the author

Bogdan Wojciszke is Professor of Psychology at the Institute of Psychology, Polish Academy of Sciences, and lectures in social psychology at the Warsaw School of Social Psychology. His research interests include social cognition and interpersonal attitudes (especially processing information on morality and competence).

Address for correspondence

Bogdan Wojciszke

Institute of Psychology

Polish Academy of Science

ul. Chodakowska 19/31

03-851 Warsaw

Poland

Tel. +48 506 143-590

Fax +48 22 5179-9917

E-mail bogdan@psychpan.waw.pl 